\title{
Studies on the Seroconversion of Attenuated Lentogenic ND Vaccine (Local Isolate) Through Drinking Water in Broiler Chicks
}

\author{
L. Sharma*, U. Biswas, C. Guha, A. Chatterjee, P.S. Jana, \\ D. Chakraborty, R. Pandey and D. Singh
}

Department of Veterinary Epidemiology and Preventive Medicine, West Bengal University of
Animal and Fishery Sciences, 37, K. B. Sarani, Kolkata-700037, India

*Corresponding author

\begin{tabular}{|l|}
\hline Ke y w o r d s \\
$\begin{array}{l}\text { Attenuated } \\
\text { lentogenic ND } \\
\text { vaccine }\end{array}$ \\
\hline Article Info \\
\hline $\begin{array}{l}\text { Accepted: } \\
\text { 10 December } 2017 \\
\text { Available Online: } \\
\text { 10 January } 2018\end{array}$ \\
\hline
\end{tabular}

A B S T R A C T

Thirty thousand commercial broiler chicks in 30 different flocks were vaccinated with live attenuated lentogenic strain ND vaccine (local isolate) through drinking water at the age of day 5 and boostered on day 26 in field condition. Serum samples were collected randomly from $10 \%$ of the vaccinated chicks before primary vaccination, before boostering and before marketing. HI antibody titre was determined from each sample as per the method OIE, 2009. Twelve birds just before marketing (at the age of $40^{\text {th }}$ day) of each 30 flocks were subdivided into two groups i.e. experimental group and vaccinated control group. Each experimental group (consists of 6 birds) was challenged with velogenic pathotype of NDV intra-nasally at the dose rate of $10^{6}$ EID $_{50}$ per bird at the age of $42^{\text {nd }}$ day and another group (consists of 6 birds) was kept as vaccinated control. Both the groups of birds were reared for next 3 weeks and recorded for any mortality/ abnormality. Serum samples were collected from all the birds at the age of $42^{\text {nd }}$ day (before challenge of the experimental group), $49^{\text {th }}, 56^{\text {th }}$ and $63^{\text {rd }}$ day of age for detection of HI antibody titre. The overall mean $\mathrm{HI}$ antibody titres were $1.53805 \pm 0.03,2.04491 \pm 0.04$ and $2.27366 \pm 0.05$ just before primary vaccination, before boostering and before marketing respectively. The overall mean antibody titre decreased significantly ( $1 \%$ level) on the $7^{\text {th }}$ day post- challenge and then increased gradually in the survived birds on the $14^{\text {th }}$ day post-challenge with $4.44 \%$ mortality and reached to peak level $(2.4075 \pm 0.08)$ on the $21^{\text {st }}$ day post-challenge in the experimental group. But in the vaccinated control groups the overall mean antibody titre gradually decreased with the advancement of age and dropped below protective level on the $63^{\text {rd }}$ day of age with no mortality/abnormality.

\section{Introduction}

Newcastle disease is a serious and common fatal disease of chicken caused by a paramyxovirus type-1. Now-a-days, various pharmaceutical private agencies and State Biologicals are producing ND vaccines in
India which are used mainly in the commercial poultry sectors (intensive poultry farms) and have limited applications in rural area (extensive production system) due to some problems like i) Heat liability ii) Affordability, iii) Cold chain for effective administration and v) Ignorance of the 
farmers. Moreover, in areas where ND is endemic, to prevent economic loss by sudden outbreak of ND, it is very important to develop a cheap but absolutely effective vaccine against the disease. The intranasal process is very cumbersum / laborious process when the flock size is very big as individual chick need to be immunized after proper controlling and is very problematic especially during boostering at the age of 25 26 days when the commercial broiler bird having the body weight in an around $1 \mathrm{~kg}$ per bird. During vaccination (handling) the birds become stressed and frequent mortality use to be reported by the poultry farmers. Therefore, an attempt was made by administering the efficacious vaccine through drinking water to evaluate its efficacy, safety and potency, so that the vaccine would be used cost effectively with ease administration and as well as accepted by the poultry farmers.

\section{Materials and Methods}

Preparation of the vaccine from working seed virus.

Determination of the HA titre of the vaccine.

Determination of $\mathrm{EID}_{50}$ for calculating the dose of live attenuated lentogenic strain (local isolate) ND vaccine.

Lyophilization of the vaccine.

Performing sterility, specificity, safety and potency tests of the lentogenic strain (local isolate) ND lyophilized vaccine.

Determination of HA titre of the lyophilized vaccine.

Performing field trial in broiler chicks to determine the immune response of the live attenuated lentogenic strain (local isolate) ND vaccine through drinking water.
Performing challenge study of the vaccinated birds in laboratory condition.

\section{Results and Discussion}

For safety test of live attenuated vaccine, chicks of the vaccinated group were oronasally instillated with 10 times doses (10 $\times 10^{6.5} \mathrm{EID}_{50}$ ) of the standard dose of the vaccine. Both the control and vaccinated group of birds were healthy up to $26^{\text {th }}$ day of age.

In potency test, 5 days old commercially broiler chicks were oro-nasally instillated with $10^{6.5}$ EID $_{50}$ live attenuated lentogenic strain vaccine (local isolate) and boostered on $26^{\text {th }}$ day of life and again challenged with $10^{6}$ EID $_{50}$ dose of velogenic strain of NDV (local isolate). All the birds in the control group died within $8^{\text {th }}$ day post-challenge and the vaccinated groups acquired $90 \%$ protection.

For farm trials, thirty thousand commercial broiler chicks in 30 different flocks were vaccinated with live attenuated lentogenic strain (local isolate) ND vaccine through drinking water at the age of day 5 (primary vaccination) and day 26 (boostering).

$\mathrm{HI}$ antibody titre was determined from $10 \%$ of the birds study before primary vaccination, before boostering and before marketing.

After primary vaccination, the protective antibody titres increased significantly. Except 9 flocks, the antibody mean titres of the rest 21 flocks were very good just before marketing which might be due to the fact that 1 flock suffered from CCRD (Chronic Contagious Respiratory Disease) after boostering, 5 flocks were complicated with colibacillosis before marketing, 2 flocks suffered from IBD before boostering and last flock had the complication of coccidiosis before boostering and IBD after boostering. 
Twelve birds just before marketing of each 30 flocks were taken and sub-divided into two groups, i.e. experimental and control groups. Experimental group birds were challenged with velogenic pathotype of NDV intranasally @ $10^{6} \mathrm{EID}_{50}$ per bird at the age of $42^{\text {nd }}$ day and another group birds were kept as vaccinated control. A total of $8(4.44 \%)$ death was recorded out of 180 challenged birds before completion of 2 weeks post-challenge. After $14^{\text {th }}$ day post-challenge, neither a bird became ill nor died in the experimental group. On the other hand, the control birds of all flocks were clinically healthy with no casualty up to the age of 63 days.

In patho-morphological study out of 8 dead birds samples inoculated into SPF eggs, embryo mortality was recorded in 4 samples $(50 \%)$ and virus was isolated from 2 samples $(25 \%)$.

The live attenuated lentogenic strain ND vaccine (local isolate) was absolutely safe and showed desirable potency in commercial broiler chicks.

The live attenuated lentogenic strain ND vaccine (local isolate) was highly potent and generated sufficient immune response when administered through drinking water in farm condition. But the immune response was not optimum when the flocks were concomitantly infected with other diseases.

The commercial birds which were vaccinated with lentogenic strain ND vaccine (local isolate) could able to withstand the challenge infection of velogenic pathotype of NDV (local isolate) with $4.44 \%$ mortality due to the other disease complications.

So, the live attenuated lentogenic strain (local isolate) ND vaccine may be considered as safe and efficacious against ND, administered orally through drinking water.

\section{Suggestion}

Newcastle disease is a great threat to the poultry farmers and a real challenge to the veterinarians to control it. The disease can be controlled by strict vaccination programme with effective vaccine.

Extensive trial with more number of birds should be undertaken on three variety of birds i.e., broiler, layer and backyard.

Live attenuated lentogenic strain (local isolate) ND vaccine is heat labile. As such highly technical experimental design is to be prepared in order to stabilize the vaccine in ambient temperature and to be used as oral thermostable vaccine in the form of feed pellet.

Attempt will be made for stability of the vaccine to reveal the shelf life of the vaccine.

\section{References}

Aini, I., 1990. Indigenous chicken production in South- East Asia. Wld. Poult.Sci.J., 46: 51-57.

Alexander, D. J., Pattison, M., and Macpherson, L. 1983. Avian Paramyxovirus of PMV 3 serotype in British turkeys. Avian Pathol.12: 469482.

Beard, C. W. and Hanson, R. P. 1984. Newcastle Disease Vaccine. In: Diseases of poultry. Edition, Iowa, USA.45: 452-470.

Bennejean 1978. Vaccinations of one-day-old chicks against Newcastledisease using inactivated oil adjuvant vaccine and/or live vaccine. Avian Pathology, 14653338, 7: 15-27.

Chulan, U. A., Ibrahim, A. L., Mustafe Babjee, A. M. and Shekhornar, A. R. 1982. Vaccination against Newcastle disease. Trop. Anim. Hlth. Prod., 14: 
177-184.

Corbanie E. A., Remon J. P., van Reeth K., Landman W.J.M., van Eck J.H.H., Vervaet C. 2007. Spray drying of an attenuated live Newcastle disease vaccine virus intended for respiratory mass vaccination of poultry. International journal of pharmaceutics.

Dasilva, M. M. and Brada, W. 1969. Congenital immunity to Newcastle disease in chicks. Pesquisa Agropec Brac., 3: 303-305.

Doyle, T. M. 1926. A hitherto unrecorded disease of fowls due to a filterpassing virus. Journal of Comparative Pathology and Therapeuti-cs, 40:144169.

Feizi, A., and Nazeri, M. 2011. Comparative Study of Antibody Titers Obtained from Avinew, Lasota, and Clone30 Vaccines in Broiler Chicks with HI Test. Australian Journal of Basic and Applied Sciences, 5(8): 554-558.

Folitse, R., Halvorson, D. A. and Sivanandan, V. 1998. Efficacy of combined killedin-oil emulsion and live Newcastle disease vaccines in chickens. Avian Dis., 42: 173-178.

Gallili, G.E., Ben-Nathan, D. 1998. Newcastle disease vaccines. Biotechnol. Adv., 16: 343-366.

Giambrone, J. J. and Closser, J. 1990. Effect of breeder vaccination on iimmunization of progeny against Newcastle disease. Avian Diseases, 34: 114-119.

Jainudeen, M.R. and Omar, A.R. 1982. The pattern of an important Fstrain NDV as spray and drinking water vaccine. Animal production and health in the tropics, Selangor (Malaysia), University, Pertanian, Malaysia, pp: 155-157.

Jayawardane, G.W.L., Spradbrow, P.B. 1995. Mucosal immunity in chickens vaccinated with the V4 strain of Newcastle disease virus. Vet. Microbiol., 46: 69-77

Ministry of food processing industries, 2009.

Musa, U., Abdu, P.A, Mera, U.M., Emmenna, P.E. and Ahmed, M.S. 2010. Vaccination with Newcastle disease vaccines strain I2 and La Sota in commercial and local chickens in plateau state Nigeria. Nigerian Veterinary Journal, 31(1): 46-55.

National Meat and Poultry Processing Board 2009. Indian Economy: Meat and Poultry Industry of India.

OIE Manual, 2009. Newcastle disease. Chapter 2.1.15. In: Office of International des Epizooties.

Reed, L.J. and Muench, L.H. 1938. A simple method of estimating fifty percent end points. Amer. J. Hygeine. 27: 493-497.

Spradbrow, P.B. 1990. Epidemiology of ND and the economy of its control. In: Proceedings Workshop of poverty eradication and promotion of gender equality March, 26-28, pp.165-173.

White, P. G. and Appleton, G. S. 1953. The speed of immune response following vaccination with B1 strain of Newcastle disease virus Amer. J. Vet. Res., 14: 609-611.

\section{How to cite this article:}

Sharma, L., U. Biswas, C. Guha, A. Chatterjee, P.S. Jana, D. Chakraborty, R. Pandey and Singh, D. 2018. Studies on the Seroconversion of Attenuated Lentogenic ND Vaccine (Local Isolate) Through Drinking Water in Broiler Chicks. Int.J.Curr.Microbiol.App.Sci. 7(01): 10361039. doi: https://doi.org/10.20546/ijcmas.2018.701.124 